\title{
Knowledge of Hemoglobin A1c and Glycemic Control in an Urban Population
}

Raafia Memon ${ }^{1,2}$, David Levitt ${ }^{1}$, Silvia R. Salgado Nunez del Prado ${ }^{1,3}$, Kashif Munir ${ }^{1}$, Elizabeth Lamos ${ }^{1}$

1. Internal Medicine/Division of Endocrinology, Diabetes and Nutrition, University of Maryland School of Medicine, Baltimore, USA 2. Internal Medicine/Endocrinology, ChristianaCare, Newark, USA 3. Division of Endocrinology, Diabetes and Metabolism, Virginia Commonwealth University, Richmond, USA

Corresponding author: Elizabeth Lamos, elamos@som.umaryland.edu

\begin{abstract}
Aim: Our study aims to assess the knowledge of hemoglobin A1c (HbA1c) and glycemic control in patients with diabetes mellitus (DM) at an urban academic institution.

Methods: This was a retrospective cross-sectional study that included a survey of 100 adult patients with DM. Our patient cohort was divided into those with recent $\mathrm{HbA1c}<8.0 \%$ and those with $\mathrm{HbA} 1 \mathrm{c} \geqslant 8.0 \%$ for subgroup analysis.
\end{abstract}

Results: The majority (71\%) of patients correctly defined HbA1c and half were aware of their HbA1c target, but they were unable to correlate the correct average blood glucose for an HbA1c level of $7 \%$. Worse control, defined as an HbA1c level of $\geqslant 8 \%$, was associated with co-morbid disease, but was not associated with understanding HbA1c definition, target or socioeconomic disparities. Perceived glycemic control was congruent with the actual control in $46 \%$ of our patients. Ninety percent of those with $\mathrm{HbA} 1 \mathrm{c} \geqslant 8 \%$ perceived their control to be better than it actually was, and $97 \%$ of those with $\mathrm{HbA} 1 \mathrm{c}<8 \%$ perceived their control worse than it actually was $(\mathrm{P}<0.00001)$.

Conclusion: Although most patients knew the definition of HbA1c, they were unable to correlate HbA1c with average blood sugar. There remain opportunities to increase education for this vulnerable population with co-morbid disease on the use of the HbA1c disease marker as an education tool.

Review began 12/08/2020 Review ended 03/14/2021 Published 03/19/2021

(๑) Copyright 2021

Memon et al. This is an open access article distributed under the terms of the Creative Commons Attribution License CC-BY 4.0., which permits unrestricted use, distribution, and reproduction in any medium, provided the original author and source are credited.
Categories: Endocrinology/Diabetes/Metabolism, Family/General Practice, Internal Medicine Keywords: diabetes, hba1c, hemoglobin a1c, glycemic control, patient perception

\section{Introduction}

The lack of understanding of patients' role in their medical care and knowledge of their chronic disease condition and therapeutic goals can often be a barrier to optimal control. Evidence suggests that patients with chronic disease, who are engaged and active participants in their medical care, have better health outcomes [1]. The hemoglobin A1c (HbA1c) test, an integral component of diabetes mellitus (DM) care, provides an index of a patient's average blood glucose (BG) level over the prior three months. It is recognized as the primary outcome measure for evaluating glycemic control and is a strong predictor of diabetes complications and related mortality risk [2]. The American Diabetes Association (ADA) and European Association for the Study of Diabetes (EASD) recommends measurement of HbA1c every three to six months depending on the stability of glycemic control [3]. Thus, as the clinical gold standard measure of glycemic control, this test provides important feedback to healthcare providers and patients.

In recent years, public health campaigns have promoted awareness in patients with diabetes regarding their target and actual HbA1c values, blood pressure and cholesterol levels, so as to be proactive in discussing these with their healthcare providers. However, data suggests that many patient populations worldwide have some, but not adequate knowledge of the HbA1c test. For example, a recent international survey of 661 patients in online health communities in the United States, Mexico, Canada and Europe reported variable awareness of their last HbA1c (42\%-89\%) and A1C target (26\%-70\%) [4]. In a study from India, greater than $70 \%$ of the subjects had awareness about the HbA1c test, but only $33 \%$ remembered their last HbA1c value and less than half of those who knew HbA1c test also knew their glycemic target [5]. Previously, researchers evaluated patient HbA1c awareness by surveying 686 U.S. adults with type 2 DM (T2DM). Of these, $66 \%$ of the respondents did not know their last HbA1c value, and only $25 \%$ of respondents accurately reported the value [6]. Poor HbA1c awareness has been demonstrated in multiple other populations [7-9] A prospective clinical case series examining HbA1c awareness in individuals receiving screening for diabetic complications demonstrated understanding of HbA1c definition in only $51 \%$ of patients examined for diabetic retinopathy [10]. Improving education of glycemic targets amongst patients may predict achievement of target HbA1c at six months [11].

The HbA1c test and interpretation can be taught both formally and informally. For example, at our 


\section{Cureus}

endocrinology and diabetes center, each examination room is equipped with a color-coded poster denoting general HbA1c target zones (blue zone HbA1c = "good control", red zone HbA1c = "improved control needed"), and depicting HbA1c to average glucose correlation [12]. Each patient receives a point-of-care HbA1c at each visit, the results and interpretation of which are provided to each patient. The objective of this study was to assess the knowledge of the HbA1c diabetes marker and glycemic control in an urban patient population.

\section{Materials And Methods}

\section{Study design}

We surveyed 100 patients with diabetes at the University of Maryland Center for Diabetes and Endocrinology (UMCDE), primarily to assess the knowledge and awareness of $\mathrm{HbA1C}$ in our patient population. Prior to survey initiation, we hypothesized that there would be a correlation between $\mathrm{HbA1C}$ awareness and better glycemic control in our population. The survey was conducted as a non-randomized, clinical cross-sectional study, along with an Institutional Review Board (IRB)-approved retrospective chart review over a fourmonth period (September and October 2016, February and March 2017).

\section{Study population}

Male and female patients with age $\geqslant 18$ and $<80$ years, who were new or established patients seen at UMCDE, willing and able to consent and complete all study procedures, were included. Subjects with any degree of cognitive impairment were excluded.

\section{Data collection}

Prior to survey administration, per IRB instruction, we obtained signed consent from patients to conduct the survey, and signed Health Insurance Portability and Accountability Act release for chart review.

Subsequently, patients were handed a paper copy of our survey, which included nine, primarily multiplechoice questions (Figure 1). 


\section{Cureus}

DO YOU HAVE DIABETES? YES $\square$ NO

PLEASE CIRCLE OR " $X$ " THE ANSWER THAT YOU CONSIDER MOST APPROPIATE:

1) Do you know what Hemoglobin AIC ("A one C" or "Glycosylated hemoglobin") is? a) $\mathrm{YES}$

b) $\mathrm{NO} / \mathrm{Never}$ heard (Please jump to question \# 3)

2) Please, mark ONE of the answers that better defines Hemoglobin A1C according to your understanding:

a) It is the value of blood sugar provided by the glucose meter (fingerstick)

b) It is the value of blood sugar in your blood tested in the laboratory

c) It is a measure of the average level of blood sugar over the past 3 months.

d) Not sure / I don't know

3) What is your target value of Hemoglobin A1C?
a) $\leq 5.7 \%$
b) $\leq 7 \%$
c) $\leq 8 \%$
d) $\leq 10 \%$
e) Not sure / I don't know

4) The last time your Hemoglobin A1C was tested, what was the value?
a) $<7 \%$
b) $7 \%-<8 \%$
c) $8 \%-<9 \%$
d) $\geq 9 \%$
e) Not sure / I don't know

5) How controlled is your diabetes? Would you say:
a) Excellent control
b) Good control
c) Fair control
d) Poor control
e) Not sure / I don't know

6) A Hemoglobin A1C of 7\% correlates with an average of blood glucose of:
a) 110
b) 150
c) 180
d) 200
e) Not sure / I don't know

7) For how long do you have Diabetes? / When was it diagnosed for first time?

8) What is your highest level of education? High school $\square \quad$ College $\square \quad$ University $\square$ None $\square$ 9) Is your household annual income?
$\leq 25,000 \square$
$20,000-50000 \square$
$50,000-75,000 \square$
$\geq 75,000 \square$

\section{FIGURE 1: Patient survey}

Subsequent to survey completion, we conducted a chart review to evaluate patient demographics (age, ethnicity, new vs. return patient), body mass index (BMI), type of DM, years since diagnosis of DM, DM regimen, history of hypertension, hyperlipidemia, whether or not patient had received diabetes education by a certified diabetes educator (CDE) and number of sessions received. Baseline demographics are summarized in Table 1.

\begin{tabular}{|c|c|c|c|}
\hline Patient characteristics & HbA1c < 8.0\%, n = 51 (\%) & HbA1c $\geq 8.0 \%, n=48$ (\%) & P-value \\
\hline Average age & $59.8 \pm 11.5$ & $52.1 \pm 13.8$ & 0.002 \\
\hline \multicolumn{4}{|l|}{ Gender (\%) } \\
\hline Male (45) & $25(49)$ & $20(41.7)$ & \multirow[t]{2}{*}{0.46} \\
\hline Female (55) & $26(51)$ & $28(58.3)$ & \\
\hline \multicolumn{4}{|l|}{ Race (\%) } \\
\hline White (24.2) & 19 (37.3) & $5(10.4)$ & \multirow{3}{*}{$0.00097^{*}$} \\
\hline African American (72.7) & $29(56.8)$ & $43(89.6)$ & \\
\hline Other (Asian, European) (3.1) & $3(5.9)$ & 0 & \\
\hline \multicolumn{4}{|l|}{ Education (\%) } \\
\hline High school/none & $26(51)$ & $31(64.6)$ & \multirow[t]{2}{*}{0.17} \\
\hline College/university & $25(49)$ & $17(35.4)$ & \\
\hline
\end{tabular}




\section{Cureus}

\begin{tabular}{|c|c|c|c|}
\hline \multicolumn{4}{|l|}{ Annual income (\%) } \\
\hline$<\$ 25,000$ & $22(43.1)$ & 19 (39.6) & \multirow{3}{*}{0.11} \\
\hline$\$ 25,000-50,000$ & $10(19.6)$ & $18(37.5)$ & \\
\hline$\$ 50,000-75,000$ & $3(6)$ & $5(10.4)$ & \\
\hline$>\$ 75,000$ & $12(23.5)$ & $4(8.3)$ & \multirow{4}{*}{0.064} \\
\hline Not reported & $4(7.8)$ & $2(4.2)$ & \\
\hline New to clinic (\%) & $4(7.8)$ & $10(20.8)$ & \\
\hline Follow-up visit & 47 (92.2) & $38(79.2)$ & \\
\hline \multicolumn{4}{|l|}{ Type of DM (\%) } \\
\hline T1DM (11.1) & $5(9.8)$ & $6(12.5)$ & \multirow{2}{*}{$0.59^{\star \star}$} \\
\hline T2DM (85.9) & $46(90.2)$ & $39(81.2)$ & \\
\hline Other (3) & 0 & $3(6.3)$ & \\
\hline Average $\mathrm{HbA1C}$ & $6.9 \pm 0.6 \%$ & $10.2 \pm 1.8 \%$ & 0.00001 \\
\hline Duration of DM (years) & $4.7 \pm 8.5$ & $5.6 \pm 8.5$ & 0.6 \\
\hline \multicolumn{4}{|l|}{ DM regimen (\%) } \\
\hline No med/orals only & $25(49)$ & $8(16.7)$ & \multirow{2}{*}{0.0028} \\
\hline Orals/GLP-1A + insulin & $16(31.4)$ & $23(47.9)$ & \\
\hline MDI & $10(19.6)$ & $17(35.4)$ & \\
\hline Average BMI & $32.3 \pm 6.2$ & $34.1 \pm 10.5$ & 0.3 \\
\hline Hypertension & $45(88)$ & $37(77)$ & \multirow{2}{*}{0.14} \\
\hline Normotensive & $6(12)$ & $11(23)$ & \\
\hline \multicolumn{4}{|l|}{ Hyperlipidemia } \\
\hline Present & 47 (92) & $35(73)$ & \multirow[t]{2}{*}{0.011} \\
\hline Absent & $4(8)$ & $13(27)$ & \\
\hline \multicolumn{3}{|l|}{ Retinopathy } & \multirow{3}{*}{0.049} \\
\hline Present & $3(6)$ & $9(19)$ & \\
\hline Absent & $48(94)$ & $39(81)$ & \\
\hline \multicolumn{3}{|l|}{ Neuropathy } & \multirow{3}{*}{1} \\
\hline Present & $17(33)$ & $16(33)$ & \\
\hline Absent & $34(67)$ & $32(67)$ & \\
\hline \multicolumn{3}{|l|}{ Nephropathy } & \multirow{3}{*}{0.009} \\
\hline Present & $6(12)$ & $16(33$ & \\
\hline Absent & $45(88)$ & $32(67)$ & \\
\hline \multicolumn{3}{|l|}{ Diabetes education } & \multirow{4}{*}{0.11} \\
\hline Yes & $33(65)$ & $38(79)$ & \\
\hline No & $18(35)$ & $10(21)$ & \\
\hline Average no. of sessions & $3.88 \pm 2.8$ & $3.71 \pm 3.5$ & \\
\hline
\end{tabular}

\section{TABLE 1: Patient demographics}

HbA1C = hemoglobin A1C, DM = diabetes mellitus, T1DM = type 1 diabetes mellitus, T2DM = type 2 DM, GLP-1 = glucagon-like peptide-1, MDI = multiple daily injection, $\mathrm{BMI}=$ body mass index. 


\section{Cureus}

\section{Statistical analysis}

For data analysis, we divided our patient cohort into those with recent HbA1c $<8.0 \%(n=51)$ and those with HbA1c $\geqslant 8.0 \%(n=49)$. Current standard of care is to provide individualized HbA1c goals for each patient [13]. For the purpose of this study, we categorized patients according to whether their actual HbA1c was above or below $8 \%$. This demarcation was intended to identify individuals by which most practitioners would agree that an $\mathrm{HbA} 1 \mathrm{c}>8 \%$ would benefit from improved control and that an $\mathrm{HbA1c}<8 \%$ would identify most patients with excellent to moderate control. For numerical data, means were calculated. T-test and chi-square tests were used for numerical and categorical data, respectively, to determine the statistical significance of any difference between the groups. In situations where the number of subjects was less than 5, Fisher's exact test was used.

\section{Results}

A survey of 100 patients was conducted. One patient's results were excluded from analysis after requesting to be withdrawn from the study.

\section{Patient demographics}

Of the 99 patients included in the analysis, $55 \%$ of the respondents were female and $45 \%$ were male (Table 1 ) . The patients in the group with $\mathrm{HbA} 1 \mathrm{c}<8 \%$ were slightly older (mean age $59.8 \pm 11.5$ years) as compared to the $\geqslant 8.0 \%$ group (mean age $52.1 \pm 13.8, \mathrm{P}$-value 0.002 ). In our patient cohort, $72.7 \%$ reported race as African American, 24.2\% non-Hispanic White, and 3.1\% as Asian or other. Information regarding race was obtained from patient's electronic medical record. Mean BMI was similar between the two HbA1c subsets. In terms of level of education, 53\% self-reported as high school graduates, 43\% reported as college/university graduates, and $4 \%$ reported no high school graduation. There was a trend toward increased higher education frequency in the $\mathrm{HbA} 1 \mathrm{c}<8.0 \%$ subset, but this was not statistically significant. Only $16.2 \%$ of our patients reported annual household income greater than $\$ 75,000$, whereas $41.4 \%$ reported annual income less than $\$ 25,000$. On the basis of income, the two HbA1c cohorts were not significantly different. The majority of patients (86\%) were established patients at the practice.

Our study cohort primary consisted of patients with T2DM (85.9\%), 11.1\% with T1DM and 3\% with other types of diabetes. In comparison, the 2015 national data from ADA reports the prevalence of T1DM amongst the DM population to be $4.13 \%$ (1.25 million) [14]. The difference between percentage of patients with type 1 versus type 2 diabetes was not statistically different between the two groups. Mean HbA1C prior to survey administration was $8.5 \pm 2.1 \%$. There was a $3.3 \%$ difference in mean $\mathrm{HbA} 1 \mathrm{C}$ between the subset of patients with $\mathrm{HbA1C}<8.0 \%$ and $\geqslant 8.0 \%$. In our patient population, the mean duration of DM was 62.4 months; however, the duration of DM was slightly longer (10 months) in the HbA1c $\geqslant 8.0 \%$ subset. Over half of our patients $(66.7 \%)$ required daily insulin (basal and/or multi-dose insulin), out of which, $61 \%$ had their last $\mathrm{HbA} 1 \mathrm{C} \geqslant 8.0 \%$. Our patient cohort had a high prevalence of comorbidities: $83 \%$ hypertension, $83 \%$ hyperlipidemia, 34\% neuropathy, $23 \%$ nephropathy, $12 \%$ retinopathy. The presence of retinopathy and nephropathy was significantly higher in the subset of patients with HbA1C $\geqslant 8.0 \%$ (P-values 0.049 and 0.009 , respectively), while hyperlipidemia was more prevalent in those with $\mathrm{HbA} 1 \mathrm{C}<8 \%$ (P-value 0.011 ).

\section{Survey responses}

The majority (71\%) of the survey respondents correctly defined HbA1c as a measure of average BG level over the preceding three months. There was no statistically significant difference between the two groups in terms of the knowledge of the correct HbA1c definition (Table 2). Despite awareness of HbA1c definition, the cohort was not as knowledgeable regarding $\mathrm{HbA} 1 \mathrm{c}$ targets or the correct BG correlate for an $\mathrm{HbA} 1 \mathrm{c}$ of $7.0 \%$. Only $15 \%$ of our patient cohort knew an HbA1C of $7.0 \%$ correlated with BG $150 \mathrm{mg} / \mathrm{dL}$, while $34 \%$ thought the BG correlate was $110 \mathrm{mg} / \mathrm{dL}$. The cohort survey responses are summarized in Table 2 . Of the patients with last $\mathrm{HbA1C}<8.0 \%, 21.6 \%$ reported an aggressive perceived $\mathrm{HbA} 1 \mathrm{c}$ target $\leqslant 5.7 \%$, with similar responses reported by the $\mathrm{HbA} 1 \mathrm{c} \geqslant 8.0 \%$ subset. Using a scale, from excellent-to-good-to-fair or poor, $83.3 \%$ of the patients with $\mathrm{HbA} 1 \mathrm{c} \geqslant 8.0 \%$ reported poor control, but $41.1 \%$ patients with $\mathrm{HbA} 1 \mathrm{c}<8.0 \%$ also reported having fair/poor glycemic control. 


\section{Cureus}

\begin{tabular}{|c|c|c|c|c|}
\hline & Total & HbA1c $<8.0 \%(n=51)$ & HbA1c $\geq 8.0 \%(n=48)$ & P-value \\
\hline Knew HbA1C definition (\%) & 83 & $41(80.3)$ & $42(87.5)$ & 0.33 \\
\hline \multicolumn{5}{|l|}{ HbA1C definition (\%) } \\
\hline Reflects POC glucose & 6 & $2(3.9)$ & $4(8.3)$ & \multirow{4}{*}{0.39} \\
\hline Reflects laboratory BG & 7 & $3(5.9)$ & $4(8.3)$ & \\
\hline Reflects 3-month BG pattern & 70 & $35(68.6)$ & $35(73)$ & \\
\hline Not sure/did not answer & 16 & $11(21.6)$ & $5(10.4)$ & \\
\hline \multicolumn{5}{|l|}{ Perceived HbA1c target (\%) } \\
\hline$\leq 5.7 \%$ & 20 & 11 (21.6) & $9(18.8)$ & \multirow{5}{*}{$0.54^{*}$} \\
\hline$<7.0 \%$ & 58 & $30(58.8)$ & $28(58.3)$ & \\
\hline$<8.0 \%$ & 4 & $1(1.9)$ & $3(6.2)$ & \\
\hline$<10.0 \%$ & 0 & 0 & 0 & \\
\hline Not sure & 17 & $9(17.7)$ & $8(16.7)$ & \\
\hline \multicolumn{5}{|l|}{ Perceived last HbA1C (\%) } \\
\hline$<7.0 \%$ & 18 & $16(31.4)$ & $2(4.2)$ & \multirow{4}{*}{$<0.00001^{\star *}$} \\
\hline $7.0 \%-<8.0 \%$ & 26 & $21(41.2)$ & $5(10.4)$ & \\
\hline$>8.0 \%$ & 35 & $2(3.9)$ & $33(68.7)$ & \\
\hline Not sure & 20 & $12(23.5)$ & $8(16.7)$ & \\
\hline \multicolumn{5}{|l|}{ Perceived DM control (\%) } \\
\hline Excellent/good & 35 & $29(57)$ & $6(12.5)$ & \multirow{3}{*}{0.00001} \\
\hline Fair/poor & 61 & $21(41.1)$ & $40(83.3)$ & \\
\hline Not sure & 3 & $1(1.9)$ & $2(4.2)$ & \\
\hline \multicolumn{5}{|l|}{ HbA1C 7\% BG correlate (\%) } \\
\hline $110 \mathrm{mg} / \mathrm{dL}$ & 34 & $18(35.3)$ & $16(33)$ & \multirow{5}{*}{0.97} \\
\hline $150 \mathrm{mg} / \mathrm{dL}$ & 15 & $7(13.7)$ & $8(17)$ & \\
\hline $180 \mathrm{mg} / \mathrm{dL}$ & 7 & $4(7.8)$ & $3(6.2)$ & \\
\hline 200 mg/dL & 5 & $2(3.9)$ & $3(6.2)$ & \\
\hline Not sure & 38 & $20(39.2)$ & $18(37.5)$ & \\
\hline
\end{tabular}

\section{TABLE 2: Survey responses}

$\mathrm{HbA1C}=$ hemoglobin $\mathrm{A} 1 \mathrm{C}, \mathrm{POC}=$ point of care, $\mathrm{BG}=$ blood glucose, $\mathrm{DM}=$ diabetes mellitus

*Due to 0 number of subjects in the group with perceived $\mathrm{HbA1c}<10 \%$, this group was excluded from analysis. Those who answered "not sure" were also excluded from the analysis.

**Those who answered "not sure" were also excluded from the analysis.

\section{Patient perception about HbA1C and DM control}

Most of our patients (80\%) reported knowing their last HbA1c (Table 3). Of these 79 patients, the perceived HbA1c was congruent with the measured HbA1c for $75 \%$ of the patients. In $46 \%$ of the total patient cohort, their perceived control was congruent with the actual control. More patients in the group with HbA1c $\geqslant 8 \%$ had their perceived control congruent with the actual control as compared to the group with $\mathrm{HbA1c}<8 \%$ ( $\mathrm{P}=$ 0.026). However, of those in whom the glycemic control was not congruent with the perceived, $89.5 \%$ of those with $\mathrm{HbA1c} \geqslant 8 \%$ perceived their control to be better than it actually was. In contrast, in the group 


\section{Cureus}

which $\mathrm{HbA1c}<8 \%, 96.9 \%$ perceived their controlled worse than it actually was $(\mathrm{P}<0.00001)$.

\begin{tabular}{|c|c|c|c|c|}
\hline & Total $(n=99)$ & HbA1c $<8.0 \%(n=51)$ & HbA1c $\geq 8.0 \%(n=48)$ & P-value \\
\hline \multicolumn{5}{|c|}{ Congruence of $\mathrm{HbA1c}$ with perception (\%) } \\
\hline Did not know last HbA1c & 20 & $12(23.5)$ & $8(16.6)$ & - \\
\hline \multicolumn{5}{|c|}{ Perceived HbA1c congruent with measured HbA1c } \\
\hline Yes & 59 & $32(62.7)$ & 27 (56.3) & 0.14 \\
\hline No & 20 & $7(13.8)$ & $13(27.1)$ & \\
\hline \multicolumn{5}{|l|}{ HBATC: } \\
\hline Perceived $<$ measured & 11 & $2(28.6)$ & $9(69.2)$ & 0.08 \\
\hline Perceived $>$ measured & 9 & $5(71.4)$ & $4(30.8)$ & \\
\hline \multicolumn{5}{|c|}{ Congruence of DM control with perception (\%) } \\
\hline Did not report control & 3 & $1(2)$ & $2(4.2)$ & - \\
\hline \multicolumn{5}{|c|}{ Perceived control congruent with actual control } \\
\hline Yes & 45 & $18(35.3)$ & 27 (56.2) & 0.026 \\
\hline No & 51 & $32(62.7)$ & 19 (39.6) & \\
\hline \multicolumn{5}{|l|}{ DM control } \\
\hline Perceived better than actual & 18 & $1(3.1)$ & $17(89.5)$ & $<0.00001$ \\
\hline Perceived worse than actual & 33 & 31 (96.9) & $2(10.5)$ & \\
\hline
\end{tabular}

TABLE 3: Patient perception about HbA1c and DM control

$\mathrm{HbA1C}=$ hemoglobin A1C, DM = diabetes mellitus

\section{Discussion}

Our study provides a cross-sectional assessment of the knowledge and perception of glycemic targets in an urban population, at an academic diabetes center. The HbA1c test is both a diagnostic test used to make management decisions and a narrative tool to place an individual's glycemic control in context of his or her disease. Because the HbA1c test is such a fundamental tool for the practitioner, understanding how the patient experiences this result is critical to a transparent practitioner/patient interaction.

Compared to previous studies, our population was more likely to know the results of their HbA1c test $[6,10]$. For example, in comparison to the U.S. study [6], in which $66 \%$ of the respondents reported not knowing their last $\mathrm{HbA} 1 \mathrm{C}$ and only $25 \%$ reporting the value accurately, $80 \%$ of our patients reported knowing their last $\mathrm{HbA} 1 \mathrm{C}$ and $60 \%$ had reported it accurately. However, there was no statistically significant difference between the two HbA1C subgroups to show if this was related to better glycemic control. Our results are encouraging, as the first step in the conversation about the usefulness of this test is for the patient to know the result. This is likely the benefit of point-of-care testing provided in this practice. The turn-around time for the result is generally less than six minutes affording the practitioner real-time results to review. The practitioners were also able to correlate the HbA1c with the last three months of BG control provided by the patient. This may reflect that most visits are on a three-month appointment cycle giving natural reinforcement of the HbA1c time frame. Additionally, our cohort correctly perceived a goal $\mathrm{HbA1c}$ target of $<7 \%$, which is generally consistent with ADA/EASD goals for most patients. While a group of individuals did perceive an even stricter HbA1c target $(\leqslant 5.7 \%)$, this was consistent across groups and may reflect patients' idealization of achieving "normal" glucose control.

Unfortunately, patients were unable to recognize the relationship between the HbA1c value and average finger stick glucose levels. Improved glycemic control, as reflected by the last HbA1c measurement, did not improve the understanding of the BG-HbA1c correlate (Table 2). Most patients perceived that an HbA1c test of $7 \%$ was associated with an average BG of $110 \mathrm{mg} / \mathrm{dL}$ rather than $150 \mathrm{mg} / \mathrm{dL}$. It reinforces that patients may not understand how to use their home glucose monitoring to assess their overall control in an accurate manner. This is an opportunity for further education. It is a nuance of the HbA1c test that can give patients more autonomy and ownership of their disease. By understanding this relationship, they can anticipate 
their $\mathrm{HbA1c}$ and glycemic control before the visit.

Our patient population was primarily African American, and this was reflected in both HbA1c groups. When the groups are compared, the $\mathrm{HbA} 1 \mathrm{c} \geqslant 8.0 \%$ group was disproportionately more African American $(90 \%, \mathrm{P}=$ 0.000097). The existence of racial and ethnic variations in the HbA1c must be taken into consideration [1517]. However, it is also thought that race may only partially explain this variation. Other socioeconomic factors that pose a barrier to care in certain ethnic groups should be studied in greater detail $[18,19]$. Further ongoing research comparing the racial difference in finger stick glucose levels and perhaps continuous glucose monitoring would be valuable. There was no difference in the duration of diabetes, whether they were new or established patients of the clinic or whether they had received diabetic education. This is in contrast to previous studies $[8,20,21]$. This does not appear to reflect the impact of socioeconomic disparities on the glycemic control and health outcomes in this urban population, as there was no difference in the education level or annual income between these groups. This finding is an opportunity for further research to understand this difference.

Interestingly, the majority of patients in the $\mathrm{HbA} 1 \mathrm{c} \geqslant 8.0 \%$ group perceived their glycemic control to be fair or poor, which is generally accurate based on their HbA1c. In addition, this group's perception of glucose control was more likely to be congruent with the actual control compared to the $\mathrm{HbA1c}<8 \%$ group. In general, the $\mathrm{HbA} 1 \mathrm{c} \geqslant 8.0 \%$ group patients are more likely to recognize that they are uncontrolled that is an opportunity to engage with the patients, reinforce goals and provide support. Additionally, individuals in the $\mathrm{HbA} 1 \mathrm{C} \geqslant 8.0 \%$ group, whose perception of control is not accurate, are more likely than the $<8 \%$ group to perceive their control to be better than it actually was. It is possible that poor control portends to improved control perception, as prior studies have demonstrated that this cohort feels physically better at higher BG levels and requires a higher hyperglycemic threshold prior to experiencing hyperglycemic symptoms [22]. This is a critical group to consider the mode in which a practitioner relays information. For some individuals, this may be auditory or visual. In this uncontrolled group whose control is poor and perception is inaccurate, it may be important to ask the patients the manner in which they learn information and to consider using teach-back methods to ascertain comprehension of the HbA1c result [23].

Interestingly, the group with $\mathrm{HbA1c}<8 \%$ whose perceived DM control was not congruent with their actual DM control were more likely to perceive their DM control as worse than it actually was. This may reflect patient's modesty, vigilance or an inaccurate reflection on expectations. Recent guidelines recommend individualized targets for glycemic control, highlighting the risks of intensive glycemic targets for different groups of individuals with DM. In this group, a discussion may include the reason(s) they cannot attain stricter control.

This study was limited to a single academic clinic with predominantly African Americans. Our results and conclusions may not apply to other populations with diabetes. Some of our survey results did fit clinical intuitions but did not achieve statistical significance. This might have improved by increasing the sample size. Assessing patient perception of teaching methods, tools and techniques may be areas of future research.

\section{Conclusions}

In conclusion, patients' education regarding their $\mathrm{HbA} 1 \mathrm{c}$ and their goal $\mathrm{HbA1c}$ level continues to be a cornerstone of the diabetes treatment plan. Although most providers would expect that the HbA1c result and the discussion regarding this important clinical test are translated to patients, there remains a disconnect for patients between their HbA1c and blood glucose monitoring.

\section{Additional Information \\ Disclosures}

Human subjects: Consent was obtained or waived by all participants in this study. Institutional Review Board, University of Maryland School of Medicine issued approval HP-00068177. Animal subjects: All authors have confirmed that this study did not involve animal subjects or tissue. Conflicts of interest: In compliance with the ICMJE uniform disclosure form, all authors declare the following: Payment/services info: All authors have declared that no financial support was received from any organization for the submitted work. Financial relationships: All authors have declared that they have no financial relationships at present or within the previous three years with any organizations that might have an interest in the submitted work. Other relationships: All authors have declared that there are no other relationships or activities that could appear to have influenced the submitted work.

\section{Acknowledgements}

We acknowledge the support of the University of Maryland, Baltimore, Institute for Clinical \& Translational Research (ICTR).

\section{References}


1. Hibbard JH, Greene J, Overton V: Patients with lower activation associated with higher costs; delivery systems should know their patients' 'scores'. Health Aff (Millwood). 2013, 32:216-222.

10.1377/hlthaff. 2012.1064

2. Laiteerapong N, Ham SA, Gao Y, Moffet HH, Liu JY, Huang ES, Karter AJ: The legacy effect in type 2 diabetes: impact of early glycemic control on future complications (the Diabetes \& Aging Study). Diabetes Care. 2019, 42:416-426. 10.2337/dc17-1144

3. American Diabetes Association: Standards of Medical Care in Diabetes - 2019. Riddle MC (ed): American Diabetes Association, 2019.

https://care.diabetesjournals.org/content/diacare/suppl/2018/12/17/42.Supplement_1.DC1/DC_42_S1_2019_UPDATED.pdf

4. Simacek K, Curran C, Fenici P, Garcia-Sanchez R: Patient perceptions of their glycemic control and its influence on type 2 diabetes outcomes: an international survey of online communities. Patient Prefer Adherence. 2019, 13:295-307. 10.2147/ppa.s186801

5. D. Manoharan, V. Viswanathan, S. Kumpatla, S: Medempudi: Knowledge and outcome measure of HbA1c testing in Asian Indian patients with type 2 diabetes from a tertiary care center. Indian J. Community Med.10.4103/0970-0218.66858. 10.4103/0970-0218.668

6. Heisler M, Piette JD, Spencer M, Kieffer E, Vijan S: The relationship between knowledge of recent HbA1c values and diabetes care understanding and self-management. Diabetes Care. 2005, 28:816-822. 10.2337/diacare.28.4.816

7. Matheka DM, Kilonzo JM, Munguti CM, Mwangi PW: Pattern, knowledge and practices of HbA1C testing among diabetic patients in a Kenyan tertiary referral hospital. Global Health. 2013, 9:55. 10.1186/17448603-9-55

8. Fisher L, Skaff M, Chesla C, Chun K, Mullan J, Gardiner P: HbA1C awareness among African and Chinese American patients with type 2 diabetes. In 64th ADA Scientific Sessions. Orlando, FL; 2004.

9. Harwell TS, Dettori N, McDowall JM, et al.: Do persons with diabetes know their (AIC) number? . Diabetes Educ. 2002, 28:99-105. 10.1177/014572170202800111

10. Do DV, Nguyen QD, Bressler NM, Schachat AP, Solomon SD, Melia M, Bressler SB: Hemoglobin A1c awareness among patients receiving eye care at a tertiary ophthalmic center. Am J Ophthalmol. 2006, 141:951-953. 10.1016/j.ajo.2005.11.057

11. Berikai P, Meyer PM, Kazlauskaite R, Savoy B, Kozik K, Fogelfeld L: Gain in patients' knowledge of diabetes management targets is associated with better glycemic control. Diabetes Care. 2007, 30:1587-1589. $10.2337 / \mathrm{dc06}-2026$

12. Nagafuchi S, Anzai K, Akazawa K, et al.: The impact of a color-classified HbA1c graph for self-monitoring and self-adjustment of long-term glycemic control. Diabetes Care. 1993, 16:1408-1409. 10.2337/diacare.16.10.1408

13. American Diabetes Association: 6. Glycemic targets. Standards of Medical Care in Diabetes - 2019 . Diabetes Care. 2019, 42:S61-S70. 10.2337/dc19-S006

14. Statistics about diabetes. http://www.diabetes.org/diabetes-basics/statistics/.

15. Herman WH, Ma Y, Uwaifo G, et al.: Differences in A1C by race and ethnicity among patients with impaired glucose tolerance in the Diabetes Prevention Program. Diabetes Care. 2007, 30:2453-2457. 10.2337/dc062003

16. Selvin E: Are there clinical implications of racial differences in HbA1c? A difference, to be a difference, must make a difference. Diabetes Care. 2016, 39:1462-1467. 10.2337/dc16-0042

17. Ziemer DC, Kolm P, Weintraub WS, et al.: Glucose-independent, black-white differences in hemoglobin A1c levels: a cross-sectional analysis of 2 studies. Ann Intern Med. 2010, 152:770-777. 10.7326/0003-4819-15212-201006150-00004

18. Bergenstal RM, Gal RL, Connor CG, et al.: Racial differences in the relationship of glucose concentrations and hemoglobin A1c levels. Ann Intern Med. 2017, 167:95-102. 10.7326/M16-2596

19. Cohen RM, Franco RS, Smith EP, Higgins JM: When HbA1c and blood glucose do not match: how much is determined by race, by genetics, by differences in mean red blood cell age?. J Clin Endocrinol Metab. 2019, 104:707-710. 10.1210/jc.2018-02409

20. Willaing I, Rogvi SA, Bøgelund M, Almdal T, Schiøtz M: Recall of HbA1c and self-management behaviours, patient activation, perception of care and diabetes distress in Type 2 diabetes. Diabet Med. 2013, 30:e139e142. $10.1111 /$ dme.12121

21. Sapkota RP, Upadhyaya T, Gurung G, Parker M, Raman R, Pardhan S: Need to improve awareness and treatment compliance in high-risk patients for diabetic complications in Nepal. BMJ Open Diabetes Res Care. 2018, 6:e000525. 10.1136/bmjdrc-2018-000525

22. Jacobson AM, Adler AG, Wolfsdorf JI, Anderson B, Derby L: Psychological characteristics of adults with IDDM: comparison of patients in poor and good glycemic control. Diabetes Care. 1990, 13:375-381. 10.2337/diacare.13.4.375

23. Ha Dinh TT, Bonner A, Clark R, Ramsbotham J, Hines S: The effectiveness of the teach-back method on adherence and self-management in health education for people with chronic disease: a systematic review. JBI Database System Rev Implement Rep. 2016, 14:210-247. 10.11124/jbisrir-2016-2296 